\title{
SIZE-FECUNDITY RELATIONSHIPS AND THEIR EVOLUTIONARY IMPLICATIONS IN FIVE DESMOGNATHINE SALAMANDERS
}

\author{
STEPHEN G. THLEY \\ Museum of Zoology, University of Michigan, Ann Arbor
}

Received June 5, 1968

The plethodontid salamander genus Desmognathus comprises seven species according to current taxonomy, of which six occur in, and four are endemic to the Appalachian Mountain system of eastern North America. Over most of the southern Blue Ridge Physiographic Province several of these forms may exist sympatrically. An apparent maximum of sympatry occurs in the Balsam Mountains of southwestern Virginia, where five species, $D$. quadramaculatus, D. monticola, D. fuscus, D. ochrophaeus, and D. wrighti occur in abundance.

Organ (1961) studied the ecological relationships and population dynamics of these species at Whitetop Mountain and Mt. Rogers in the Balsam Mountains. Hairston (1949) compared the ecologies of $D$. quadramaculatus, $D$. monticola, $D$. ochrophaeus, and D. wrighti in the Black Mountains of North Carolina where those four forms occur sympatrically. Both authors found that, in the order given above, these species form a series in which decreasing size is paralleled by an increasing tendency toward terrestrial habits. Organ further found that the trend is also paralleled by increasing juvenile survivorship. He concluded that heavier juvenile mortality is associated with aquatic sites, and that $D$. quadramaculatus, D. monticola, D. fuscus, $D$. ochrophaeus, and $D$. wrighti represent an evolutionary trend in which selection has favored progressively more terrestrial habits.

Size and egg production are positively correlated in the genus Desmognathus, as they are in many animals. Organ (1961) also emphasized that the larger species lay larger clutches than the smaller ones, and that the evolutionary trend within the genus has been "the gradual transformation of a population with a high egg production and low survival into a population with low egg production and a high survival to maturity." He found no differences in number of clutches per year or age at maturity that might compensate for differences in clutch size.

This paper attempts to further explore and compare the relationships between size and fecundity among the five sympatric species of Desmognathus and to elaborate on the hypotheses drawn by Organ relative to evolutionary trends in reproductive habits. In particular I have sought to determine whether fecundity differences among the five species are explained simply by differences in their sizes, or whether sizefecundity relationships are more complex.

\section{Materials aNd Methods}

This study is based mainly on Organ's series of Desmognathus from the Balsam Mountains. With regard to the species wrighti and quadramaculatus, I restricted this study to these series. I have included specimens of $D$. monticola from western North Carolina in addition to specimens from the Balsam Mountains in an attempt to include more of the total snout-vent length range for that species. Data on series of $D$. ochrophaeus from the vicinity of Highlands, North Carolina and D. fuscus from Licking County, Ohio are included where comparisons with Balsam Mountain material of those two species are appropriate.

Whenever possible, only females with eggs greater than $1 \mathrm{~mm}$ in diameter were examined. Otherwise it was difficult to distinguish smaller eggs from those to be deposited the following year, since in the 
early stages of yolk deposition egg sizes are so variable as to obscure the differences between the clutches of successive years.

Snout-vent length measures the distance from the tip of the snout to the posterior angle of the vent. The method of covariance analysis was utilized to compare the slopes and elevations of the regression lines for the five species, using the methods and forms of calculations given in Snedecor (1956). The squared deviations and cross products of deviations were calculated from computer calculated raw sums, sums of squares, and sums of cross products. In the case of $D$. quadramaculatus rounding error prevented the use of computer calculated raw sums, and hand-calculated sums were used instead.

\section{SUMMARY OF HABITS AND LIFE HISTORIES}

The following accounts are based primarily on the studies of Hairston and Organ, supplemented in certain cases by my own observations.

\section{Female Reproductive Cycles}

Organ concluded that all five of the species deposit eggs biennially, but Martof and Rose (1963) found evidence for annual egg laying in $D$. ochrophaeus in the southern Appalachians. Tilley and Tinkle (1968) have presented evidence for an annual or possibly even biannual cycle in $D$. ochrophaeus in the vicinity of Mt. Mitchell and in the Balsam Mountains. Spight (1967) concluded that $D$. fuscus deposits eggs annually in eastern North Carolina and Harrison (1967) found that a sixth' species, $D$. aeneus, also lays annually. Martof (1962) found evidence for biennial reproduction in another desmognathine, Leurognathus marmoratus.

The same weaknesses which Tilley and Tinkle found in the arguments for biennial egg laying in $D$. ochrophaeus probably apply as well to $D$. wrighti, $D$. fuscus, $D$. monticola, and $D$. quadramaculatus. Spight's study bears this out for D. fuscus.
Harrison's work indicates that annual egg laying may occur in $D$. aeneus. The evidence for bienniality in Leurognathus is not, in my opinion, compelling. In view of these arguments it would seem dangerous to assume bienniality in $D$. wrighti, $D$. monticola, and D. quadramaculatus. While more data on this point are sorely needed, I shall assume all five species dealt with here to be annual reproducers.

\section{Nesting Habits}

All five species exhibit parental care, in which the females remain with the eggs until hatching. Pope (1924) found that females of $D$. monticola and $D$. quadramaculatus attach each egg individually to the roof of the nesting cavity so that the eggs form a flat mass one or two eggs thick, whereas $D$. fuscus, $D$. ochrophaeus, and $D$. wrighti (information on the latter species from Organ, 1961) generally deposit their eggs in spherical clusters with only a few actually attached to the roof of the nesting cavity.

Females of the five species utilize somewhat different sites for egg deposition. $D$. quadramaculatus utilizes the most aquatic sites, depositing eggs on the undersides of rocks in the beds of streams and beneath small waterfalls. D. monticola, $D$. ochrophaeus, and $D$. wrighti deposit eggs in less aquatic sites than $D$. quadramaculatus, beneath stream banks and, in the case of $D$. ochrophaeus, beneath moss on rocks and logs in seepage areas. $D$. fuscus appears to lay eggs in situations intermediate between those utilized by $D$. quadramaculatus and those used by the other species.

\section{Length of the Larval Period}

The length of the larval period varies greatly among the five species, and reflects the aquatic to terrestrial trend discussed above. In the terrestrial $D$. wrighti metamorphosis occurs prior to hatching (one wonders, therefore, why it deposits its eggs in aquatic sites). Organ gave estimates of 26-28 months for D. quadramaculatus, 12- 


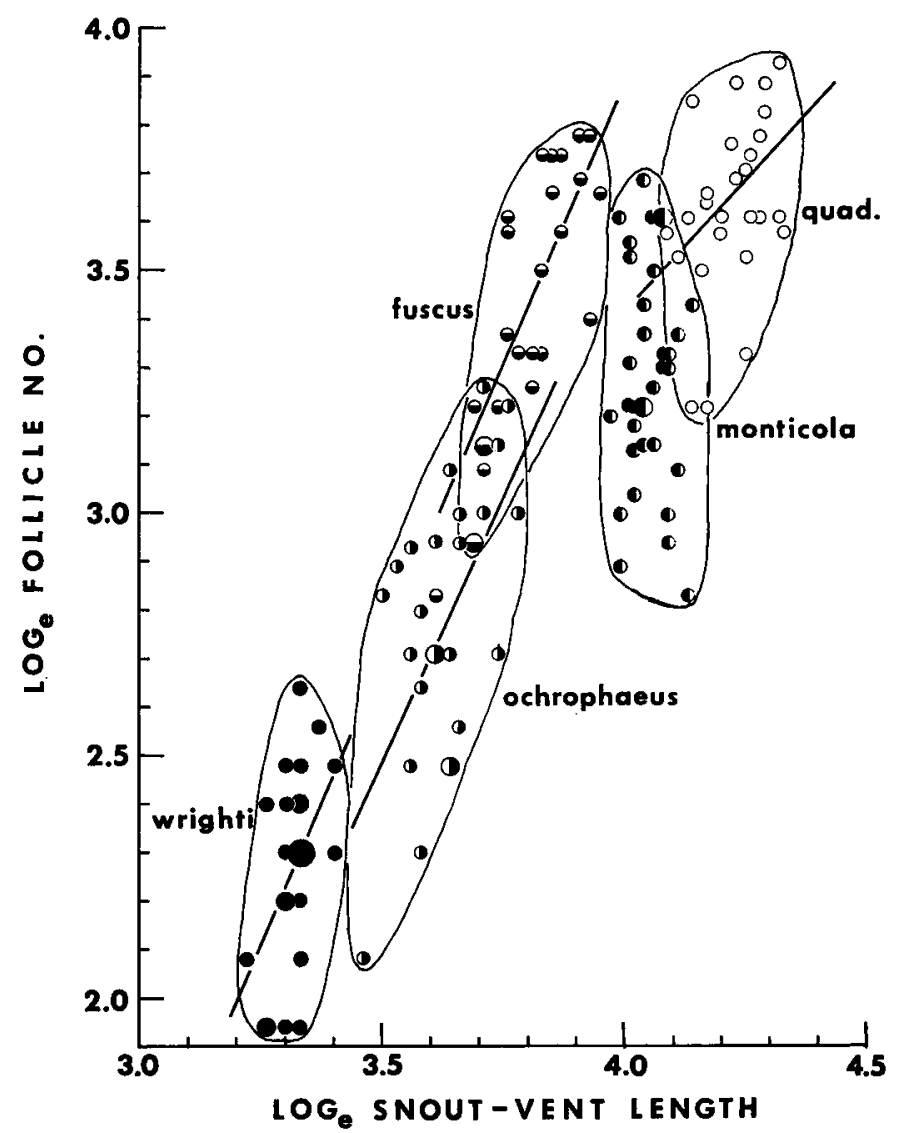

Frg. 1. Relationships between size and fecundity in five species of Desmognathus. Lines represent least squares regression lines of $\log _{e}$ follicle number on $\log _{e}$ snout-vent length.

13 months for $D$. monticola, 13-16 months for $D$. fuscus, and 10-11 months for $D$. ochrophaeus. The estimate for $D$. ochrophaeus is in error (Tilley and Tinkle, 1968); the larval period of that species is from 4 to 6 months at Mt. Mitchell, North Carolina.

\section{Age at Maturity}

Organ estimated that males of all five species matured at 3.5 years of age, while Spight (1967) estimated 3 years for males of $D$. fuscus. Both authors concluded that females require an additional year to produce their first clutch of eggs.

\section{Habitats}

D. quadramaculatus occurs chiefly in larger and faster streams, while $D$. monti- cola prefers the banks of streams, as does D. fuscus. Organ found that both $D$. ochrophaeus and $D$. wrighti occur in terrestrial situations. Males of both species are largely terrestrial during the summer months, moving to aquatic sites such as seepage areas and spring heads during the winter. His data, as well as Hairston's and my own observations, indicate that of the two, $D$. wrighti is the more terrestrial. The aquatic sites preferred by $D$. ochrophaeus are of the seepage area-spring head variety, rather than the stream or stream side habitats occupied by D. quadramaculatus and D. monticola.

The species are also segregated altitudinally to a certain degree. $D$. ochrophaeus occurs from the lowest to the highest avail- 
TABLE 1. Summary of regression data. $\mathrm{n}=$ sample size, $\mathrm{r}=$ correlation coefficient. Equations and correlation coefficients are for regressions of loge follicle number on $\log _{e}$ snout-vent length. $v=B a l s a m$ Mountains (Virginia), $o=$ Ohio.

\begin{tabular}{lcccc}
\hline \hline \multicolumn{1}{c}{ Species } & $n$ & $r$ & $\begin{array}{c}\text { Significance } \\
\text { level }\end{array}$ & $\begin{array}{c}\text { Regression } \\
\text { equation }\end{array}$ \\
\hline D. wrighti & 23 & 0.458 & 0.050 & $Y=2.4130 X-5.7235$ \\
D. ochrophaeus & 25 & 0.598 & 0.010 & $Y=2.1773 X-5.1407$ \\
D.fuscus (v) & 26 & 0.837 & 0.001 & $Y=2.2845 X-5.2727$ \\
D.fuscus (o) & 18 & 0.687 & 0.010 & $Y=1.7484 X-3.3944$ \\
D. monticola & 35 & -0.163 & $<0.100$ & - \\
D. quadramac. & 26 & 0.390 & 0.050 & $Y=1.0700 X-0.8825$ \\
\hline
\end{tabular}

able habitats in the Appalachians. In the Balsam Mountains $D$. fuscus has a similar distribution, but does not extend as high as does $D$. ochrophaeus, while $D$. quadramaculatus and $D$. monticola occur from the lowest elevations in the Balsam Mountains to just above 5000 feet. Organ found that $D$. fuscus and D. monticola have mutually exclusive distributions, with $D$. fuscus occupying the banks of the headwaters of streams at high elevations and $D$. monticola occupying the banks of streams at lower elevations. $D$. wrighti is essentially a high elevation species, whose populations reach their maximum densities in the spruce-fir forests of the southern Appalachians. However, it extends to as low as 3000 feet near Mt. Mitchell (personal observation and Hairston, 1949) and Organ found it as low as 3500 feet in the Balsam Mountains.

\section{Results}

Figure 1 shows the relationship between snout-vent length and follicle number in the five species studied. Plots of the untransformed data were curvilinear, presumably because follicle number is a function of body volume rather than body length. Furthermore, the variance in follicle number was positively correlated with snoutvent length. For these reasons both variables were converted to their natural logarithms, which are plotted in Figure 1. All of the statistics discussed below are based on the natural logarithms of the data.

The $\log _{\mathrm{e}}-\log _{\mathrm{e}}$ transformation succeeded in making the variances along the regres- sion lines relatively homogeneous, but not in removing all of the curvilinearity. $D$. wrighti appears to have somewhat higher $\log _{e}$ follicle number values than might have been expected from extrapolation from the regression for $D$. ochrophaeus. D. quadramaculatus, on the other hand, appears to have slightly lower values. Table 1 gives the correlation coefficients and regression equations for the five species, Table 2 the results of the covariance analyses in which the regression for $D$. ochrophaeus was compared with those for the other four species. Whereas there is a suggestion of curvilinearity when all the species are graphed together, the regressions for $D$. wrighti and D. quadramaculatus do not differ significantly from that for $D$. ochrophaeus at the five percent level, neither with respect to the slopes nor to the elevations of the regression lines (Tables 2 and 3 ). The analysis suggests, rather, that the relationship between snout-vent length and fecundity is identical in the species wrighti, ochrophaeus, and quadramaculatus.

Since the correlation coefficient for $D$. monticola is insignificant (in fact, negative) at the five percent level, that species was excluded from the covariance analysis. The hypothesis that $D$. monticola lies on the regression line common to $D$. wrighti, $D$. ochrophaeus, and D. quadramaculatus was tested as follows: A single regression line was calculated for the three species, having the equation $Y=1.5027 X-2.7020$. From this equation the mean $\log _{\mathrm{e}}$ follicle number corresponding to the mean $\log _{\mathrm{e}}$ snout-vent length' was calculated (3.3931). This value 
TABLE 2. Summary of covariance analyses. F tests for similarity of slopes and elevations constructed as in Snedecor, 1956. Subscripts as in Table 1. Based on $\log _{0}-\log _{\text {e }}$ transform.

\begin{tabular}{|c|c|c|c|c|c|c|}
\hline \multirow[b]{2}{*}{ Test } & \multicolumn{2}{|c|}{ Slopes } & \multicolumn{2}{|c|}{ Elevations } & \multicolumn{2}{|c|}{ Conclusions } \\
\hline & $F$ & $\begin{array}{c}\text { Significance } \\
\text { level }\end{array}$ & F & $\begin{array}{c}\text { Significance } \\
\text { level }\end{array}$ & $\frac{}{\text { Slopes }}$ & Elevations \\
\hline Overall (less monticola) & 1.100 & $<0.05$ & 27.235 & 0.01 & equal & different \\
\hline ochrophaeus vs. wrighti & 0.040 & $<0.05$ & 1.754 & $<0.05$ & equal & equal \\
\hline ochrophaeus vs. fuscus (v) & 0.024 & $<0.05$ & 10.273 & 0.01 & equal & different \\
\hline ochrophaeus vs. fuscus (o) & 0.282 & $<0.05$ & 4.495 & 0.05 & equal & different \\
\hline ochrophaeus vs. quadramac. & 1.821 & $<0.05$ & 0.349 & $<0.05$ & equal & equal \\
\hline fuscus (v) vs. fuscus (o) & 0.786 & $<0.05$ & 5.373 & 0.05 & equal & different \\
\hline
\end{tabular}

was compared with the actual value for $D$. monticola (3.3001) by means of a $t$-test. The resultant $t=2.1577$, $\mathrm{df}=33$ is significant at the five percent level. Thus $D$. monticola appears to lay somewhat fewer than the expected number of eggs.

In order to further test the hypothesis that the relationship between clutch size and body size is the same in both $D$. wrighti and $D$. ochrophaeus, the clutch sizes of female $D$. wrighti were compared with those of very small female $D$. ochrophaeus from the southwestern portion of the latter's range near Highlands, North Carolina. These data were not analyzed statistically but, as shown in Figure 2, female $D$. ochrophaeus of the same size range as $D$. wrighti lay approximately the same number of eggs.

The overall covariance analysis (excluding D. monticola) shown in Tables 2 and 3 indicates that all five species lie on lines with the same slope, but that the hypothesis that all lie on a single line is rejected at the one percent level. Comparison of $D$. ochrophaeus with the other species has shown that it lies on the same regression line as $D$. wrighti and $D$. quadramaculatus but on a different line from $D$. fuscus. At any given size then, $D$. fuscus lays more eggs than $D$. ochrophaeus whereas the increase in fecundity per unit increase in size is the same for all the species. The mean number of eggs carried by females of $D$. fuscus examined (31.4), in fact, exceeded the mean number contained in females of $D$. monticola (28.1), although the difference is not significant at the five percent level $(t=1.0057, .4>P>.3)$. Thus $D$. fuscus, for its size, has a higher fecundity than any of the other species.

The Balsam Mountain region is one of the few areas in the Blue Ridge Physiographic Province where $D$. fuscus occurs, and is perhaps the only part of its extensive range where it is sympatric with as many other species of Desmognathus. It seemed possible, therefore, that the reproductive properties of the species in the Balsams might differ from those in other parts of its range. In order to test for such differences, the regression in the Balsam Mountain material was compared with that in a series of 19 females from Licking County, Ohio (UMMZ 125516-17). One of the latter was discarded from the analysis because she contained abnormally few follicles. The regressions are superimposed in Figure 3, and the results of the covariance analysis comparing them are given in Tables 2 and 3. The difference between the slopes is not significant at the five percent level but that between the elevations of the regression lines is, the elevation for the Balsam Mountain series being higher. Furthermore, the Balsam Mountain specimens are larger. Both of these factors would appear to indicate that $D$. fuscus in that region are considerably more fecund than at least those from the Ohio population.

The covariance analysis also indicates that Ohio specimens differ significantly from $D$. ochrophaeus, although less than Balsam Mountain D. fuscus do. 


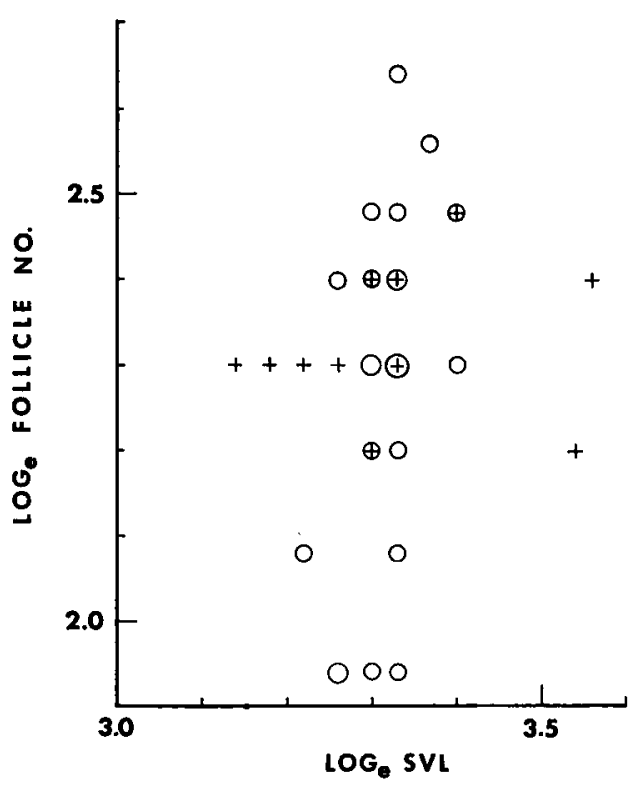

FIG. 2. Relationships between size and fecundity in Desmognathus wrighti (circles) from the Balsam Mountains and D. ochrophaeus (crosses) from Cullasaja Gorge near Highlands, North Carolina. Regression lines and transformations as in Fig. 1.

Assuming a constant egg volume-body volume relationship in the five species, the regression of clutch size on body length would appear to indicate that a reasonably constant relationship is maintained between clutch volume and body volume, at least among the species wrighti, ochrophaeus, and quadramaculatus. From the comparison of regressions one might expect that the ratio of clutch volume to body volume is higher in $D$. fuscus and lower in $D$. monticola. Ratios were calculated for the specimens examined, and their means among the five species are compared in Figure 4 . The clutch volumes were based on the diameters of the largest eggs, found in each of the species. These were: $D$. wrighti, $2.5 \mathrm{~mm}$; D. ochrophaeus, $3.0 \mathrm{~mm}$; D. fuscus, $3.0 \mathrm{~mm} ; D$. monticola, $4.0 \mathrm{~mm}$; and $D$. quadramaculatus, $4.0 \mathrm{~mm}$. Body volumes were calculated as perfect cylinders using snout-vent length as length and width at the axilla as diameter. The ratios of axillary width to snout-vent length were

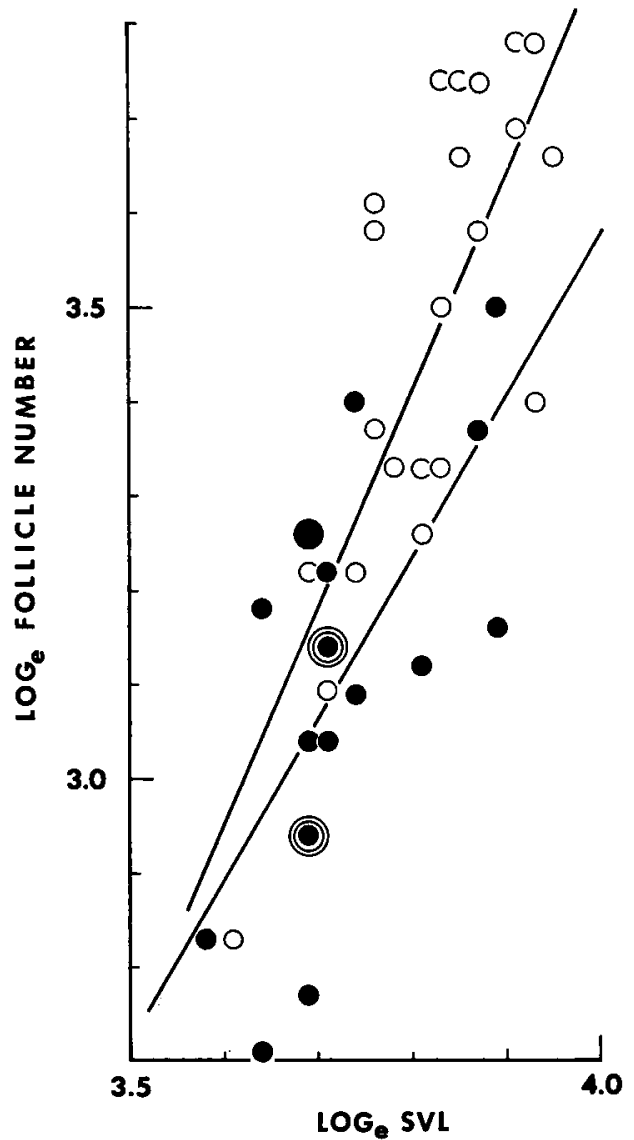

FIc. 3. Relationships between size and fecundity in $D$. fuscus from the Balsam Mountains (hollow circles) and Ohio (solid circles). Regression lines and transformations as in Fig. 1.

compared among the five species. Those species between which the ratios did not differ significantly at the five percent level were all assigned the ratios' mean value for those species. Trunk-length to body-length ratios were also compared and found not to differ significantly at the five percent level among the five species. Thus snoutvent length could be used to compute body volumes. Body volumes were then calculated as the following functions of snoutvent lengths: $D$. wrighti, $D$. ochrophaeus, and $D$. fuscus, $V=.0142\left(S V L^{3}\right) ; D$. monticola, $V=.0191\left(S V L^{3}\right)$; and $D$. quadramaculatus, $V=.0172\left(S V L^{3}\right)$. 
TABLE 3. Details of individual covariance analyses, constructed after Snedecor, 1956. $\mathrm{f}=$ degrees of freedom; $\mathrm{x}=$ deviations from log. mean snout-vent lengths, $\mathrm{y}=$ deviations from $\log _{\mathrm{g}}$ mean follicle numbers, $\mathrm{b}=$ slopes, $\mathrm{SS}=$ sum of squared deviations from regression line, $\mathrm{MS}=$ mean squared deviations from regression line (residual variances).

\begin{tabular}{|c|c|c|c|c|c|c|c|c|}
\hline \multirow[b]{2}{*}{ Source } & \multicolumn{4}{|c|}{ Deviations from means } & \multicolumn{4}{|c|}{ Deviations from reg. } \\
\hline & $f$ & $\Sigma x^{2}$ & $\Sigma x y$ & $\Sigma y^{2}$ & $b$ & $i$ & SS & $M S$ \\
\hline wrighti & 22 & 0.0414 & 0.0999 & 0.9482 & 2.4130 & 21 & 0.7071 & 0.0336 \\
\hline ochrophaeus & 24 & 0.1618 & 0.3523 & 2.1465 & 2.1773 & 23 & 1.3795 & 0.0599 \\
\hline fuscus & 25 & 0.2390 & 0.5460 & 2.0302 & 2.2845 & 24 & 0.7829 & 0.0326 \\
\hline quadramac. & 25 & 0.1128 & 0.1207 & 0.8542 & 1.0700 & 24 & 0.7251 & 0.0302 \\
\hline Pooled & & & & & & 92 & 3.5946 & 0.0390 \\
\hline Reg. coef. & & & & & & 3 & 0.1288 & 0.0429 \\
\hline Common & & 0.5550 & 1.1189 & 5.9791 & 2.0160 & 95 & 3.7234 & 0.0391 \\
\hline Adj. means & & & & & & 3 & 3.1948 & 1.0649 \\
\hline Total & & 11.1105 & 17.3461 & 33.9995 & & 98 & 6.9182 & \\
\hline ochrophaeus & 24 & 0.1618 & 0.3523 & 2.1465 & 2.1773 & 23 & 1.3795 & 0.0599 \\
\hline wrighti & 22 & 0.0414 & 0.0999 & 0.9482 & 2.4130 & 21 & 0.7071 & 0.0336 \\
\hline Pooled & & & & & & 44 & 2.0866 & 0.0474 \\
\hline Reg. coef. & & & & & & 1 & 0.0019 & 0.0019 \\
\hline Common & & 0.2032 & 0.4522 & 3.0947 & 2.2253 & 45 & 2.0885 & 0.0464 \\
\hline Adj. means & & & & & & 1 & 0.0814 & 0.0814 \\
\hline Total & & 1.3800 & 2.2639 & 5.8838 & & 46 & 2.1699 & \\
\hline ochrophaeus & 24 & 0.1618 & 0.3523 & 2.1465 & 2.1773 & 23 & 1.3795 & 0.0599 \\
\hline fuscus (v) & 25 & 0.2390 & 0.5460 & 2.0302 & 2.2845 & 24 & 0.7829 & 0.0326 \\
\hline Pooled & & & & & & 47 & 2.1624 & 0.0460 \\
\hline Reg. coef. & & & & & & 1 & 0.0011 & 0.0011 \\
\hline Common & & 0.4008 & 0.8983 & 4.1767 & 2.2412 & 48 & 2.1635 & 0.0450 \\
\hline Adj. means & & & & & & 1 & 0.4623 & 0.4623 \\
\hline Total & & 0.7731 & 2.3092 & 9.5231 & & 49 & 2.6258 & \\
\hline ochrophaeus & 24 & 0.1618 & 0.3523 & 2.1465 & 2.1773 & 23 & 1.3795 & 0.0599 \\
\hline quadramac. & 25 & 0.1128 & 0.1207 & 0.8542 & 1.0700 & 24 & 0.7251 & 0.0302 \\
\hline Pooled & & & & & & 47 & 2.1046 & 0.0447 \\
\hline Reg. coef. & & & & & & 1 & 0.0814 & 0.0814 \\
\hline Common & & 0.2746 & 0.4730 & 3.0007 & 1.7225 & 48 & 2.1860 & 0.0455 \\
\hline Adj. means & & & & & & 1 & 0.0159 & 0.0159 \\
\hline Total & & 4.7530 & 7.0763 & 12.7371 & & 49 & 2.2019 & \\
\hline fuscus (v) & 25 & 0.2390 & 0.5460 & 2.0302 & 2.2845 & 24 & 0.7829 & 0.0326 \\
\hline fuscus (o) & 17 & 0.1276 & 0.2231 & 0.8261 & 1.7484 & 16 & 0.4360 & 0.0256 \\
\hline Pooled & & & & & & 40 & 1.2189 & 0.0304 \\
\hline Reg. coef. & & & & & & 1 & 0.0239 & 0.0239 \\
\hline Common & & 0.3666 & 0.7691 & 2.8563 & 2.0979 & 41 & 1.2428 & 0.0303 \\
\hline Adj. means & & & & & & 1 & 0.1628 & 0.1628 \\
\hline Total & & 0.4247 & 0.9956 & 3.7394 & & 42 & 1.4056 & \\
\hline ochrophaeus & 24 & 0.1618 & 0.3523 & 2.1465 & 2.1773 & 23 & 1.3795 & 0.0599 \\
\hline fuscus (o) & 17 & 0.1276 & 0.2231 & 0.8261 & 1.7484 & 16 & 0.4360 & 0.0256 \\
\hline Pooled & & & & & & 39 & 1.8155 & 0.0465 \\
\hline Reg. coef. & & & & & & 1 & 0.0131 & 0.0131 \\
\hline Common & & 0.2894 & 0.5754 & 2.9726 & 1.9882 & 40 & 1.8286 & 0.0457 \\
\hline Adj. means & & & & & & 1 & 0.2162 & 0.2162 \\
\hline Total & & 0.3878 & 0.9404 & 4.3253 & & 41 & 2.0448 & \\
\hline
\end{tabular}


The ratios for the five species are graphed in Figure 4. Non-overlap of the black boxes, representing twice the standard error on either side of the means, indicates mean differences significant at approximately the five percent level. As expected from the covariance analysis, D. fuscus is characterized by the highest ratios of the five species, and differs significantly from all but $D$. ochrophaeus. The mean ratio for $D$. ochrophaeus is significantly higher than those for $D$. wrighti and $D$. quadramaculatus. No significant differences occur among the latter three species. Thus, while D. wrighti, D. ochrophaeus, and D. quadramaculatus lie on the same regression line when follicle number is plotted against snout-vent length, this regression does not maintain a constant clutch volume-body volume ratio among the three species using the criteria for calculating clutch and body volumes given above.

\section{Discussion}

Fecundity is only one of many variables subject to adjustment by natural selection in the maximization of individual fitness. In the genus Desmognathus fecundity is intimately related to body size, both within and between species. At the interspecific level, however, this relationship is not perfect. Considering the variety of habitats exploited by the species dealt with here, perhaps it is closer than one would intuitively expect, particularly among the series wrighti, ochrophaeus, and quadramaculatus. Any theory concerned with the evolutionary modification of demographic parameters in the genus Desmognathus must somehow explain both the overall closeness of this relationship and its imperfections.

One means of reconciling the similarity of the relationship in these species with the diversity of their habitats would be to conclude that selection is able to increase fecundity only by increasing body size, and that high fecundities are selectively advantageous in aquatic habitats. This would ignore the imperfections of the relationship

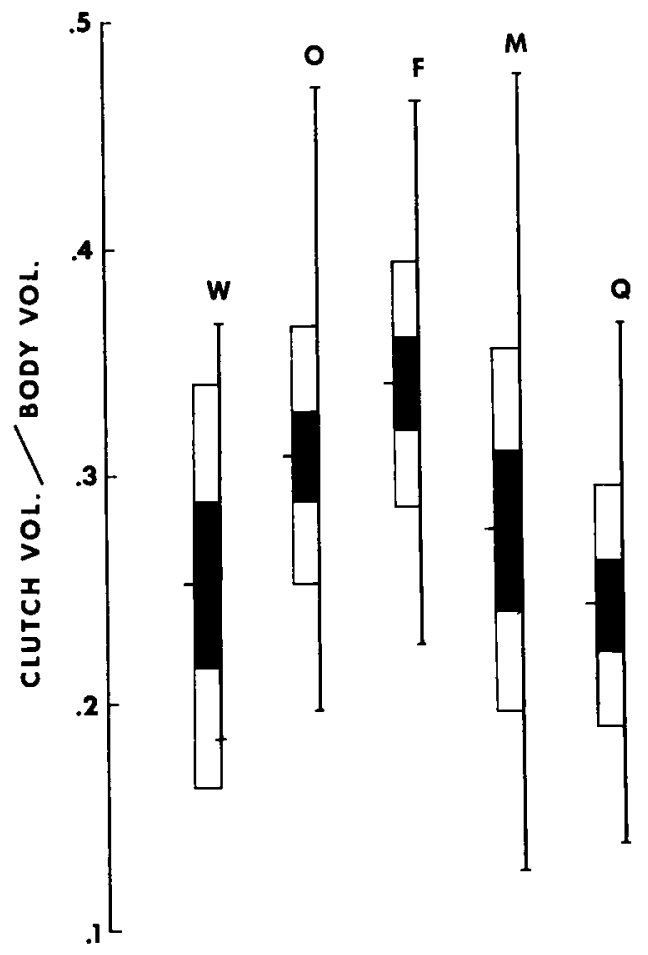

Fic. 4. Comparison of clutch volume-body volume ratios among the five species of Desmognathus. Solid boxes represent twice the standard error, hollow boxes one standard deviation on either side of each mean.

between size and fecundity and, more seriously, leaves unanswered the question of the selective advantage of high fecundity in aquatic habitats. Organ's (1961) data show mortality to be heavier in such situations, but to hypothesize that this results in selection for increased fecundity violates the arguments of Lack (1954), who pointed out that high mortality rates result from high fecundities.

Assuming, as most authors have, that aquatic situations are the ancestral habitat of the genus Desmognathus (Dunn, 1926; Wake, 1966), and that body size differences were established in advance of terrestrial tendencies in the smaller forms, selection operating whenever the various species came into contact might have re- 


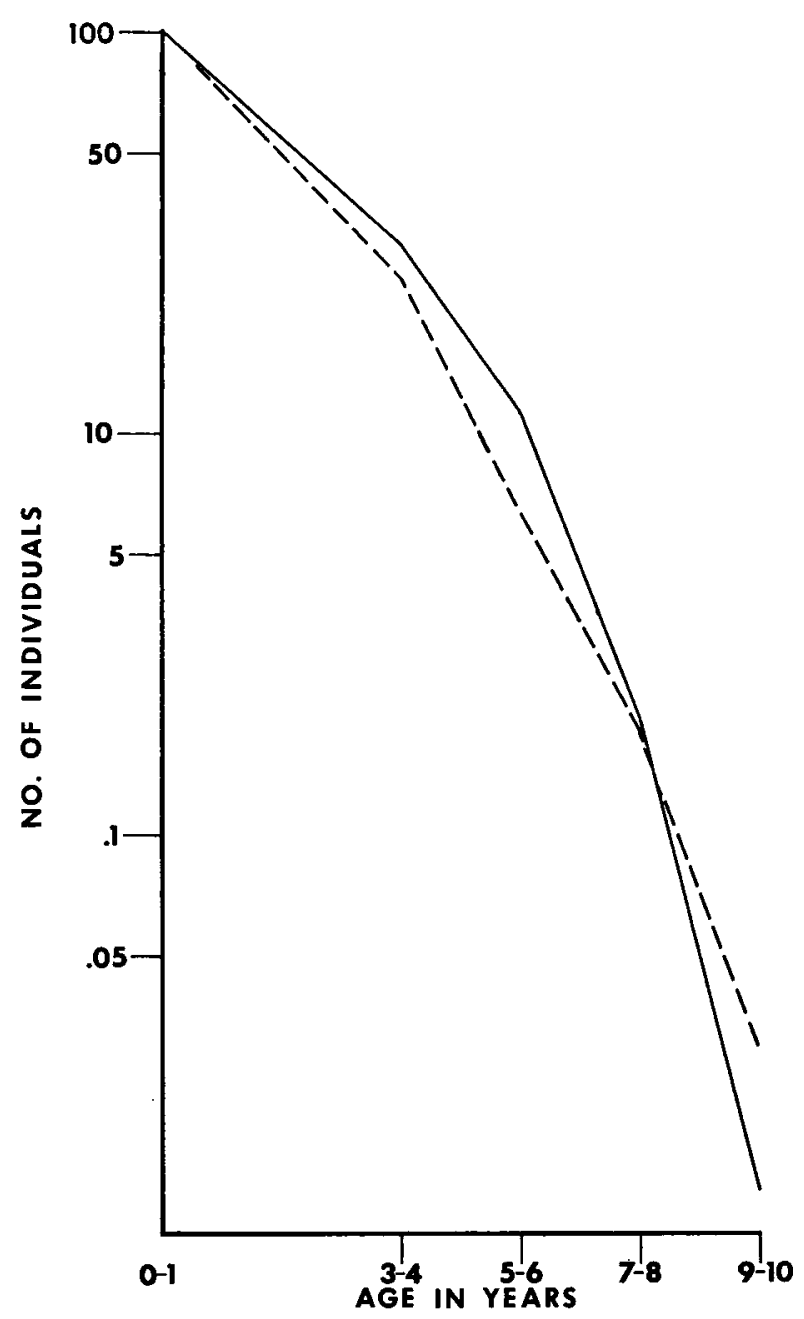

F.c. 5. Survivorship curves for males of $D$. fuscus (solid line) and $D$. monticola (broken line) from the Balsam Mountains. Data on numbers of individuals in successive year classes from Organ, 1961. See text for additional explanation.

sulted in their displacement into different habitats. Terrestrial tendencies would have been most strongly favored in the smaller forms, since these were (and still are) subject to predation by larger salamanders. The latter, by virtue of their size, would have been able to remain in the ancestral habitat.

The data presented in this paper indicate that positive size-fecundity correlations are evident both within and between the species examined. It seems reasonable to assume that such correlations also held among the ancestors of the present forms, so that the larger forms were also the most fecund, just as they are today. This, in turn, would have led to the higher juvenile mortality rates among aquatic species that Organ observed in his data.

The data on clutch volume-body volume ratios suggest that egg size, as well as clutch size has been altered in the evolution 
of the reproductive rates of the forms studied. Thus $D$. ochrophaeus, while it lies on the same size-fecundity regression line as $D$. wrighti and D. quadramaculatus, is characterized by a higher clutch volumebody volume ratio than either of those two species. D. monticola, on the other hand, lays fewer eggs than expected from the wrighti-ochrophaeus-quadramaculatus regression, but evidently amasses the same relative volume of yolk per clutch.

Clutch volume-body volume ratios are probably more meaningful indications of the actual amount of effort expended at each reproduction than are clutch sizes alone, and do not appear to correlate at all closely with the aquatic to terrestrial trend. $D$. fuscus is particularly discrepant in this regard (Fig. 4), as well as in its average clutch size (Fig. 1). Of the five species considered here, $D$. fuscus is the only one in which the adults have not evolved some means of minimizing predation by larger salamanders in aquatic habitats. D. quadramaculatus and $D$. monticola share the advantage of large size. Mature males of $D$. ochrophaeus and both sexes of $D$. wrighti are largely terrestrial during most of the year. The fact that brooding females of both $D$. ochrophaeus and $D$. fuscus are probably subjected to heavier mortality than the other species should cause selection to favor greater reproductive efforts per season (Williams, 1966). Figure 5 compares the survivorship curves for males of $D$. fuscus and D. monticola, based on Organ's data for numbers of males in different year classes and mine on fecundities (Organ assumed a larger clutch size in $D$. monticola, based on clutches of the two species that he found in the field). The curves, similar as they are, do indicate slightly lower adult survivorship in $D$. fuscus. Since in these two species both sexes occupy similar habitats, female survivorship curves of the two should exhibit a similar relationship to one another. Organ estimated the mean annual survival rate of brooding females of $D$. fuscus to be the lowest of the five species. However, since he concluded that the species had a biennial laying cycle he also assumed that he could distinguish between females that had brooded during the previous year and those which would produce eggs during the current year, and used this information to calculate the mean annual survival rate for brooding females. Since Martof and Rose (1963) and Tilley and Tinkle (1968) have presented reasons for doubting the presence of a biennial laying cycle, the groups of animals that Organ compared probably did not represent groups of females that were depositing eggs in successive years. Thus, with our present inability to age female salamanders, it is extremely doubtful whether survivorship curves can be constructed for that sex.

If the shorter adult life expectancy of $D$. fuscus is in fact attributable to predation by large aquatic Desmognathus, one might expect the reproductive effort per season of individuals free of that source of mortality to be lower. Figure 3 indicates that this may in fact be the case. Female $D$. fuscus from the Balsam Mountains do lay more eggs than those from the Licking County, Ohio population. This is attributable both to their larger size and to a different size-fecundity relationship, whereby for any given size, females of the Balsam Mountain population lay more eggs than females from Ohio. Perhaps their larger size is also an adaptation directed toward increased fecundity.

The fact that $D$. fuscus combines relatively small size and aquatic habits may account for its absence throughout most of the southern Blue Ridge Physiographic Province, in which its preferred habitats are occupied by larger salamanders. As suggested by Dunn (1926) and Organ (1961), competition with $D$. monticola, as well as predation by it and other large salamanders, may be important in determining the distribution of $D$. fuscus.

\section{SUMmary}

Size and fecundity are positively correlated in four of the five species of Desmog- 
nathus inhabiting the Balsam Mountains of southwestern Virginia. This correlation is manifest both inter- and intraspecifically.

Size-fecundity relationships are identical in $D$. wrighti, $D$. ochrophaeus, and $D$. quadramaculatus, while $D$. fuscus has a higher and $D$. monticola a lower fecundity than expected by extrapolation of the common regression for the other three species. $D$. fuscus and D. ochrophaeus both exhibit higher clutch volume-body volume ratios than do the other species.

It is hypothesized that selection has favored terrestrial tendencies in the smaller species because of their vulnerability to predation by larger aquatic salamanders. The fact that the smaller species are necessarily less fecund has resulted in their exhibiting lower mortality rates. The relatively high reproductive efforts of $D$. fuscus and $D$. ochrophaeus may result from their combining relatively small size with aquatic habits.

\section{ACKNOWLEDGMENTS}

I wish to thank Dr. Donald W. Tinkle, Dr. Charles F. Walker, Dr. Richard C. Bruce, and Kraig Adler for their criticisms of the manuscript, Dr. Tinkle and Dr. James A. Organ for the numerous discussions that led to its inception, and my wife, Mary for her assistance in its preparation. This research was supported by National Science Foundation Grant GB-6230 to the University of Michigan, for research in systematic and evolutionary biology.

\section{Literature Cited}

HaLrston, N. G. 1949. The local distribution and ecology of the plethodontid salamanders of the southern Appalachians. Ecol. Monog. 19:47-73.

Harrison, J. R. 1967. Observations on the life history, ecology and distribution of Desmognathus aeneus aeneus Brown and Bishop. Amer. Mid. Natur. 77(2):356-370.

LACK, D. 1954. The evolution of reproductive rates. In J. S. Huxley, A. C. Hardy, E. B. Ford (eds.), Evolution as a process. Allen and Unwin, London.

MartoF, B. S. 1962. Some aspects of the life history and ecology of the salamander Leurognathus. Amer. Mid. Natur. 67(1):1-35.

Martof, B. S., ANd F. L. Rose. 1963. Geographic variation in southern populations of Desmognathus ochrophaeus. Amer. Mid. Natur. 69(2):376-425.

Organ, J. A. 1961. Studies of the local distribution, life history, and population dynamics of the salamander genus Desmognathus in Virginia. Ecol. Monog. 31:189-220.

Pope, C. H. 1924. Notes on North Carolina salamanders, with especial reference to the egglaying habits of Leurognathus and Desmognathus. Amer. Mus. Nov. 306:1-19.

SNEDECOR, G. W. 1956. Statistical methods. Iowa State Univ. Press, Ames.

Spight, T. M. 1967. Population structure and biomass production by a stream salamander. Amer. Mid. Natur. 78(2):437-447.

Tilley, S. G., AND D. W. Tinkle. 1968. A reinterpretation of the reproductive cycle and demography of the salamander Desmognathus ochrophaeus. Copeia 1968(2):299-303.

WAKE, D. B. 1966. Comparative osteology and evolution of the lungless salamanders, family Plethodontidae. Mem. S. California Acad. Sci. 4:1-111.

Wriliams, G. C. 1966. Natural selection, the costs of reproduction, and a refinement of Lack's principle. Amer. Natur. 100(916):687-690. 